\title{
OPEN Coral cover surveys corroborate predictions on reef adaptive potential to thermal stress
}

\author{
Oliver Selmoni ${ }^{1,2}$, Gaël Lecellier ${ }^{2,3}$, Laurent Vigliola ${ }^{2}$, Véronique Berteaux-Lecellier ${ }^{2,4}$ \& \\ Stéphane Joost ${ }^{1,4} \bowtie$
}

As anomalous heat waves are causing the widespread decline of coral reefs worldwide, there is an urgent need to identify coral populations tolerant to thermal stress. Heat stress adaptive potential is the degree of tolerance expected from evolutionary processes and, for a given reef, depends on the arrival of propagules from reefs exposed to recurrent thermal stress. For this reason, assessing spatial patterns of thermal adaptation and reef connectivity is of paramount importance to inform conservation strategies. In this work, we applied a seascape genomics framework to characterize the spatial patterns of thermal adaptation and connectivity for coral reefs of New Caledonia (Southern Pacific). In this approach, remote sensing of seascape conditions was combined with genomic data from three coral species. For every reef of the region, we computed a probability of heat stress adaptation, and two indices forecasting inbound and outbound connectivity. We then compared our indicators to field survey data, and observed that decrease of coral cover after heat stress was lower at reefs predicted with high probability of adaptation and inbound connectivity. Last, we discussed how these indicators can be used to inform local conservation strategies and preserve the adaptive potential of New Caledonian reefs.

Coral bleaching is one of the main causes of severe declines of coral reefs around the world ${ }^{1-3}$. This phenomenon is mainly caused by anomalous heat waves leading to the death of hard-skeleton corals, which are the cornerstone of reefs ${ }^{2}$. Over the last 30 years mass coral bleaching events repeatedly struck worldwide, causing losses of local coral cover up to $50 \%{ }^{1,3}$. In the coming years, bleaching conditions are expected to occur more frequently and to become persistent by $2050^{4}$. As up to one third of marine wildlife depends on coral reefs for survival and at least 500 million people livelihoods worldwide ${ }^{5}$, there is an urgent need to define new strategies to improve the preservation of these ecosystems ${ }^{6}$.

Recent research reported reefs that rebounded from repeated heat stress and showed an increased thermal resistance ${ }^{7-11}$. Adaptation of corals against heat stress might explain such observations ${ }^{12,13}$. Under this view, identifying adapted coral populations is of paramount importance, as conservation strategies might be established to protect reefs hosting these corals from local stressors (e.g. via marine protected areas, MPAs) ${ }^{14}$. Furthermore, adapted corals could be of use in reef restoration plans and repopulate damaged reefs ${ }^{15}$. The adaptive potential of corals at a given reef depends on the arrival of propagules from reefs exposed to recurrent thermal stress ${ }^{16,17}$. This is why characterizing spatial patterns of thermal adaptation and reef connectivity is crucial to empower the conservation of the adaptive potential of corals ${ }^{16,17}$.

Seascape genomics is a powerful method to evaluate spatial patterns of environmental variation and connectivity ${ }^{17,18}$. This method relies on a thorough analysis of environmental conditions around reefs using satellite data. Daily records of surface temperature are remotely sensed using satellites, and processed to compute indicators of thermal patterns associated with bleaching events ${ }^{17,19,20}$. Corals exposed to different thermal patterns are then sampled and genotyped to identify genetic variants correlated with these indicators ${ }^{17,18}$. The association between genetic variants and a given indicator defines a model of adaptation that can be used to predict the probability of adaptation, based on the value of the indicator itself ${ }^{17,21}$. In addition, by remote sensing sea current movements, it is possible to draw a connectivity map between every reef within an area of interest. This can be done using spatial graphs that resume multi-generational dispersal matching spatial patterns of genetic diversity in a given species ${ }^{22}$. This approach results in indices of connectivity defining, for a reef of interest, the

${ }^{1}$ Laboratory of Geographic Information Systems, Ecole Polytechnique Federale de Lausanne, Lausanne, Switzerland. 'UMR250/9220 ENTROPIE IRD-CNRS-Ifremer-UNC-UR, Labex CORAIL, Nouméa, New Caledonia, France. ${ }^{3}$ UVSO, Université de Paris-Saclay, Versailles, France. ${ }^{4}$ These authors contributed equally: Véronique Berteaux-Lecellier and Stéphane Joost. ${ }^{\square}$ email: stephane.joost@epfl.ch 


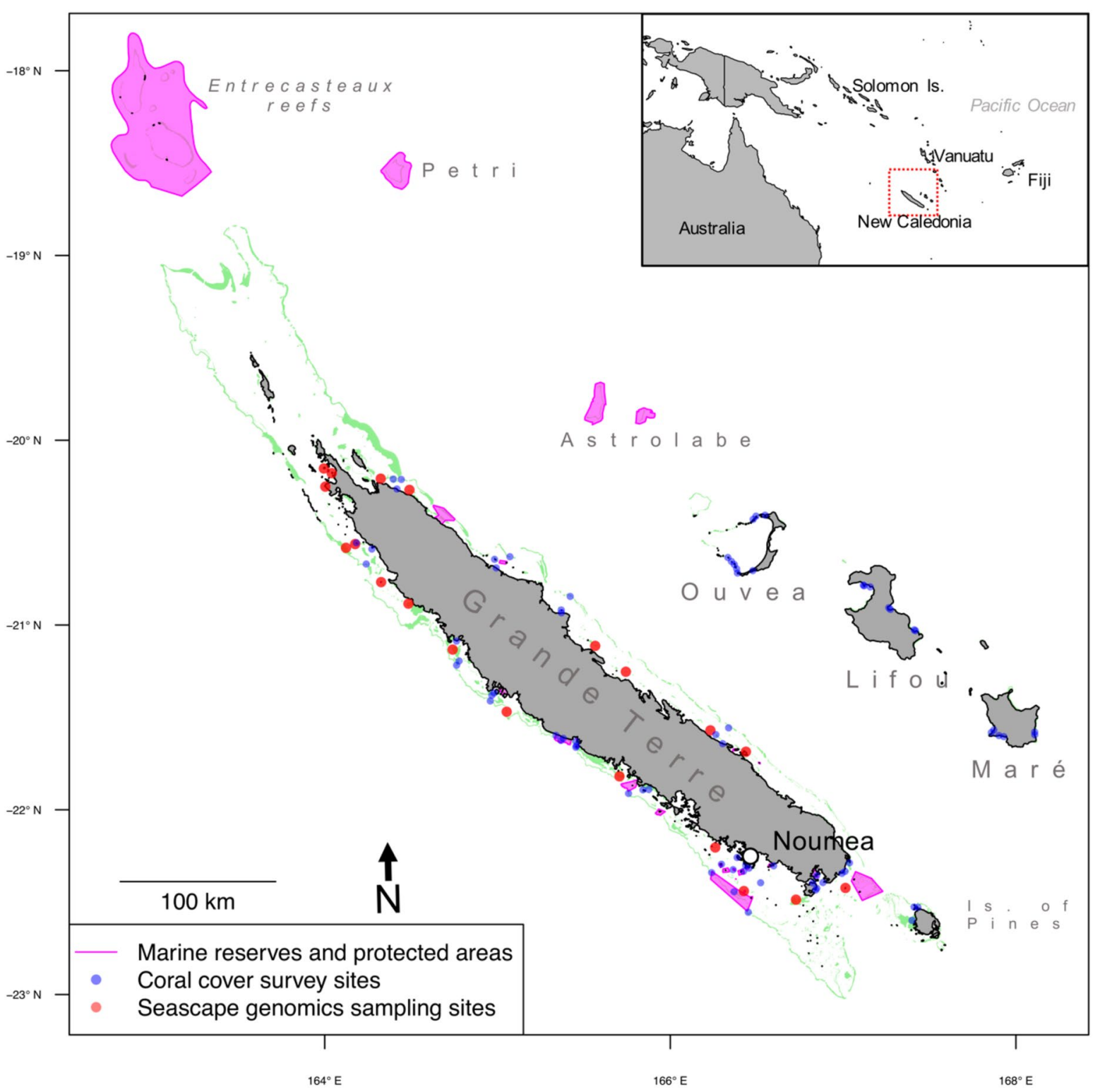

Figure 1. Reef system of New Caledonia. Coral reefs are highlighted in green. The blue dots correspond to sites of coral cover survey of the New Caledonian observational network of coral reef ${ }^{24}$. The red dots correspond to the sampling locations of coral specimen (permits No 609011-/2018/DEPART/JJC and No 783-2018/ARR/ DENV) for the seascape genomics study that provide genetic data in the present study ${ }^{23}$. Sea regions highlighted in purple correspond to the marine reserves and protected areas as catalogued by the French agency for MPAs (https://www.aires-marines.fr/). Map prepared using R (v. 3.5 $5^{53}$ ).

predisposition in sending (outbound connectivity) and receiving (inbound connectivity) propagules to/from neighboring reefs ${ }^{17}$.

In this study, we predicted spatial patterns of heat stress adaptation and connectivity for over $1000 \mathrm{~km}$ of coral reefs of New Caledonia, in the Southern Pacific (Fig. 1). The study area encompassed the barrier reef surrounding Grande Terre, the main islands of the Archipelago, as well as the intermediary and fringing enclosed in the lagoon. We also considered reefs surrounding the Loyalty Islands (Ouvéa, Lifou and Maré) and the Astrolabe (east of Grande Terre) and those in the Entrecasteaux and Petri atolls (north of Grande Terre). We first used remote sensing data to (1) evaluate the thermal variability of the study area and (2) estimate patterns of sea current connectivity between reefs. Next, we employed genomic data from a seascape genomics study on three coral species of the region ${ }^{23}$ in order to (1) compute the probability of adaptation to heat stress across the whole region, and (2) verify whether predicted sea current connectivity between reefs matched the genetic structure of coral populations. Last, we compared our predictions with field surveys of living coral cover recorded by the New Caledonian observational network of coral reef $\left(\mathrm{RORC}^{24}\right)$. Our results suggest that negative effects of recent heat stress on coral cover are mitigated at reefs predicted with high probability of heat stress adaptation and inbound connectivity. We then discuss the conservation status of reefs around New Caledonia, and assess how 


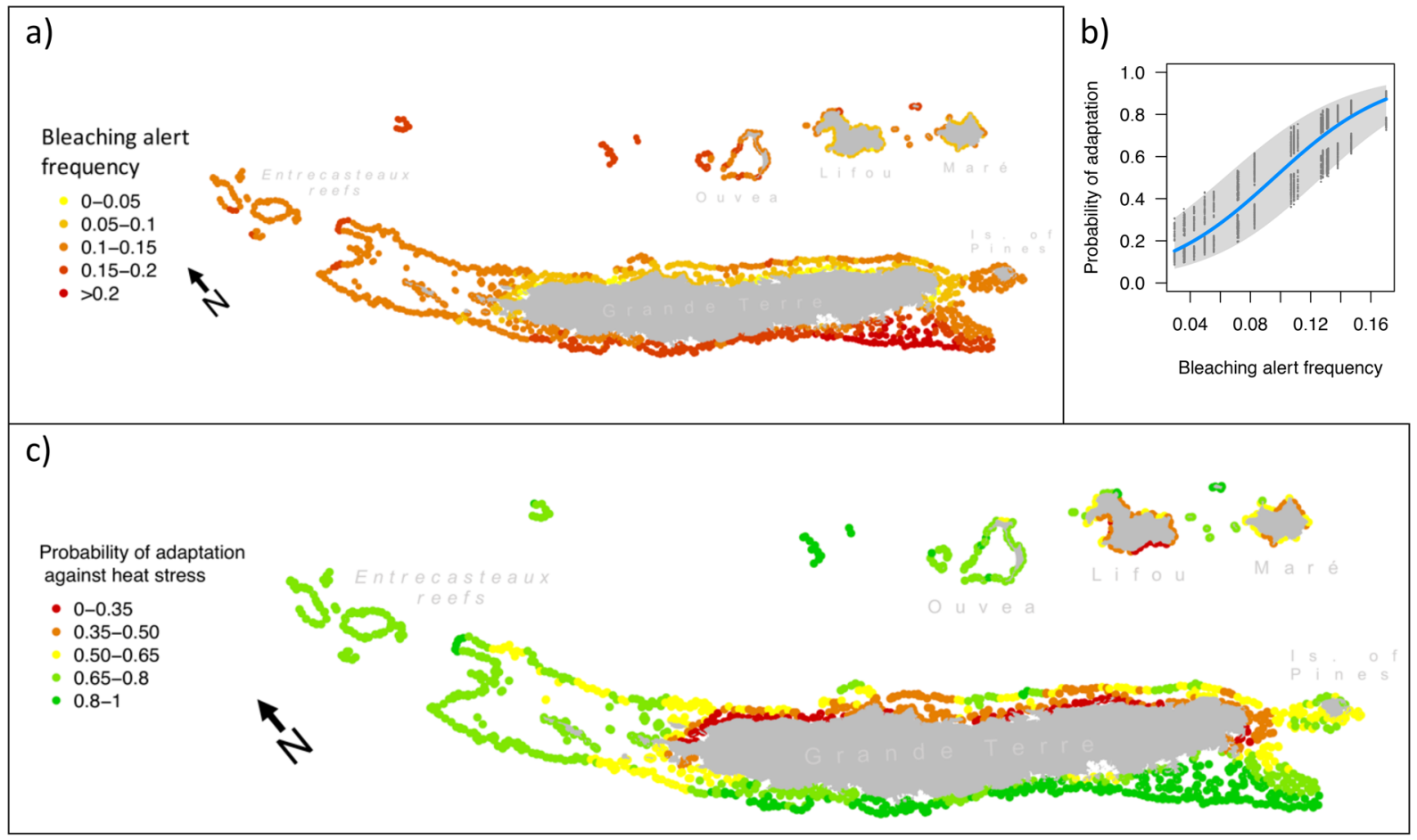

Figure 2. Bleaching alert frequency and probability of heat stress adaptation. In (a), bleaching alert frequency $\left(\mathrm{BAF}_{\text {overall }}\right)$ is displayed for each reef of New Caledonia. This value is derived from remote sensing data of sea surface temperature, and describes the frequency of cumulated heat stress conditions that can lead to bleaching. In (b), a logistic model of heat stress adaptation is shown. This model is based on the frequencies of potentially adaptive genotypes of three coral species of New Caledonia ${ }^{23}$. The plot displays the probability of adaptation to heat stress as a logistic function of $\mathrm{BAF}_{\text {overall }}$ (blue line, with the grey band showing the $95 \%$ interval of confidence). The model shown in (b) was used to translate $\mathrm{BAF}_{\text {overall }}$ displayed in (a) in the probability of adaptation $\left(\mathrm{PA}_{\mathrm{HEAT}}\right)$ against heat stress. The map in (c) displays $\mathrm{PA}_{\mathrm{HEAT}}$ for every reef of New Caledonia. Maps prepared using R (v. $\left.3.5^{53}\right)$.

conservation indices of probability of adaptation and connectivity can be used to protect the adaptive potential of corals of the region.

\section{Results}

Heat stress and probability of adaptation. The remote sensing data of sea surface temperature since 1985 were processed to calculate the frequency of bleaching alert conditions $\left(\mathrm{BAF}_{\text {overall }}\right)$ across the reef

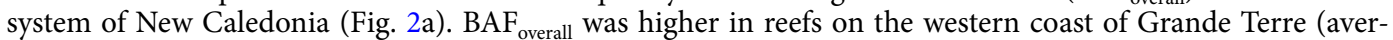
age BAF: $0.16 \pm 0.04)$ than in those on the eastern coast $(0.08 \pm 0.03)$. Reefs in Lifou, Maré and Isle of Pines displayed $\mathrm{BAF}_{\text {overall }}$ values comparable to those on the eastern coast of Grande Terre $(0.09 \pm 0.03,0.10 \pm 0.02$ and $0.11 \pm 0.01$, respectively), while in Ouvéa and Entrecasteaux reefs the $\mathrm{BAF}_{\text {overall }}$ values $(0.15 \pm 0.01$ and $0.12 \pm 0.01$, respectively) were closer to the values observed on the western coast.

Previous seascape genomics analyses on three corals of the region (Acropora millepora, Pocillopora damicornis and Pocillopora acuta) revealed the presence of multiple genetic variants ( 32 in total) potentially implicated in heat stress resistance ${ }^{23}$. We employed these data to construct logistic genotype-environment association models defining the expected frequency of potentially adaptive genetic variants as a function of $\mathrm{BAF}_{\text {overall }}$. We then used a "leave-one-population-out" cross-validation method and found that, in all the three species, the expected frequencies of adaptive genotypes were correlated with the observed ones (A. millepora: $\mathrm{r}=0.52 \pm 0.09$, P. damicornis: $\mathrm{r}=0.55 \pm 0.16, P$. acuta: $\mathrm{r}=0.6 \pm 0.08$; Fig. S1). As a comparison, the same cross-validation method applied to 1000 randomly selected genetic variants resulted weak correlations between expected and observed frequencies (A. millepora: $\mathrm{r}=-0.2 \pm 0.32$, P. damicornis: $\mathrm{r}=-0.07 \pm 0.36$, P. acuta: $\mathrm{r}=-0.09 \pm 0.37$ ).

We then constructed a unique model of heat stress adaptation combining all the genotype-environment association models across the three species and defining the overall probability of presence of potentially adaptive variants $\left(\mathrm{PA}_{\mathrm{HEAT}}\right)$ as a function of $\mathrm{BAF}_{\text {overall }}(\mathrm{Fig}$. 2b). This model was then used to produce a map of predicted $\mathrm{PA}_{\mathrm{HEAT}}$ values for the whole region (Fig. $2 \mathrm{c}$ ). It revealed accentuated differences compared with $\mathrm{BAF}_{\text {overall }}$ patterns, with $\mathrm{PA}_{\mathrm{HEAT}}$ generally above 0.65 in reefs on the western coast of Grande Terre, Isle of Pines, Entrecasteaux and Ouvéa. In contrast, values below 0.35 were observed at reefs located along the east coast of Grande Terre, in Lifou and Maré. 
a) Acropora millepora

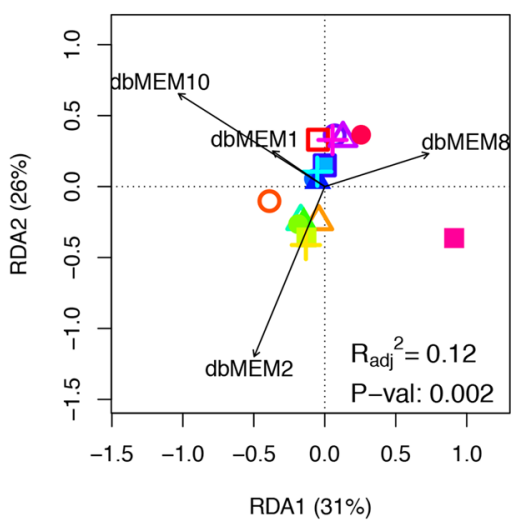

b) Pocillopora damicornis

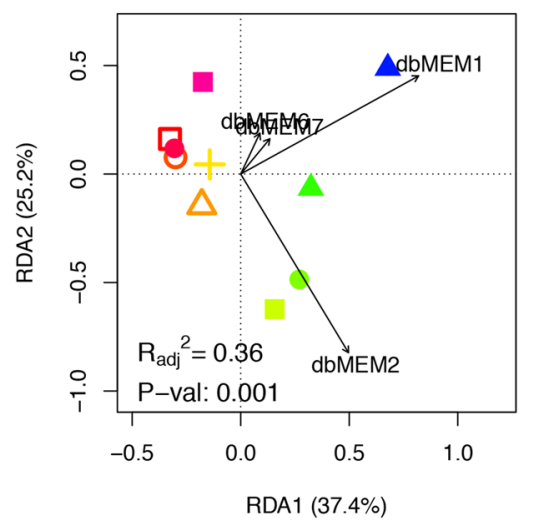

c) Pocillopora acuta

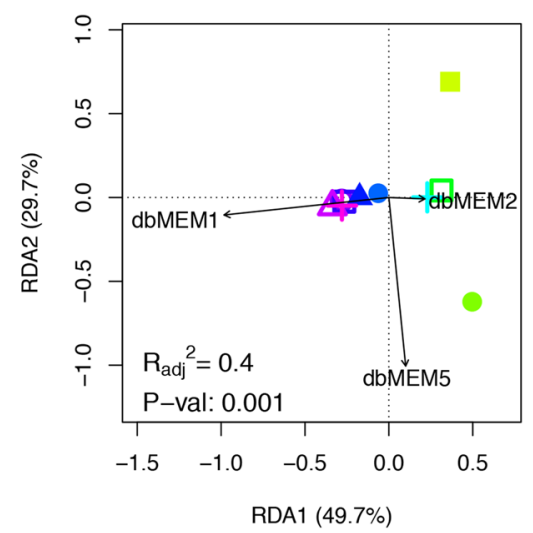

d)

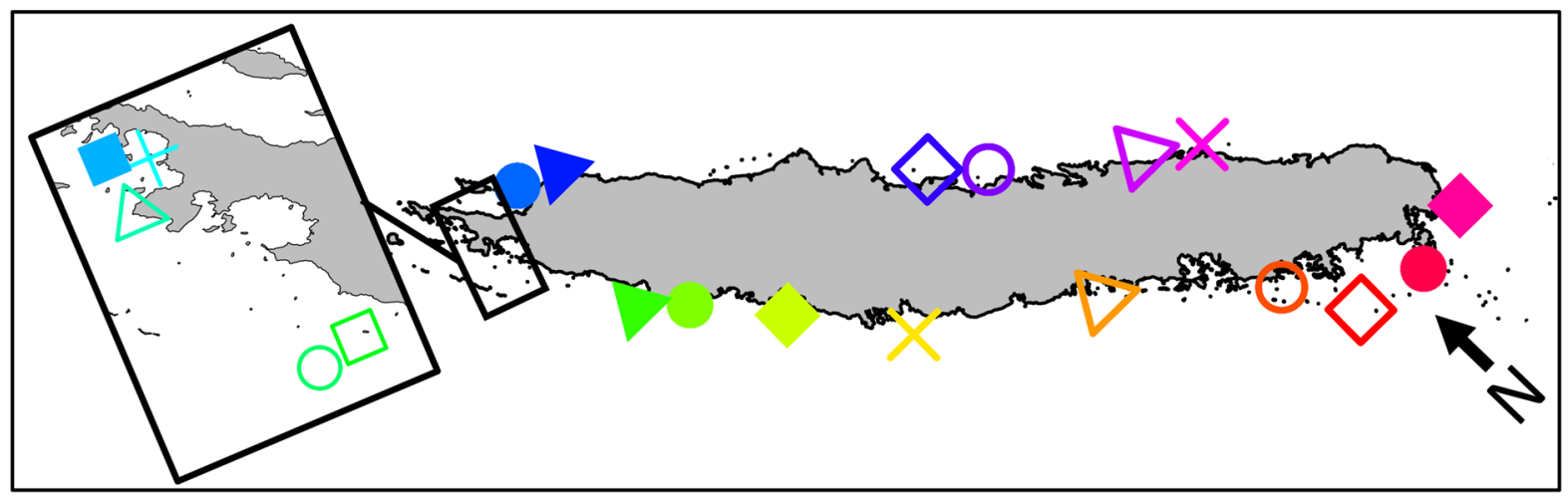

Figure 3. Seascape cost distance and genetic structure of coral populations. Plots a-c display the results of the redundancy analysis (RDA) between the genetic structure of three coral populations of New Caledonia (a: Acropora millepora, b: Pocillopora damicornis, c: Pocillopora acuta) and the connectivity between reefs. Genetic structure was computed as the principal component analysis of the allelic frequencies among different sampling sites (shown in the map in $\mathrm{d}$, prepared using $\mathrm{R}$ v. $3.5^{53}$ ). Connectivity between reefs is represented by distance-based Moran's eigenvector maps (dbMEMs), which are variables summarizing the patterns of leastcost-distances between sites. These least-cost-distances were computed using a seascape graph based on remote sensing of oceanic currents. RDA on the three species showed that the patterns of genetic diversity among sampling sites (i.e. the position of the symbols on the RDA axes) matched patterns of connectivity (i.e. the black arrows of dbMEMs). For all the species such association resulted as significant under analysis of variance $(\mathrm{p}<0.01)$.

Reef connectivity and genetic structure of coral populations. Remote sensing of sea currents was used to compute a spatial graph of seascape connectivity predicting cost distances between reefs of New Caledonia. By using a redundancy analysis (RDA), we investigated whether such predictions on reef distances (summarized in distance-based Moran's eigenvector maps; dbMEMs) were representative proxies of the genetic population structure of corals of the region (summarized using a principal component analysis of allelic frequencies).

In three studied species (A. millepora, P. damicornis and P. acuta), we found that the genetic structure between corals sampled at specific sites was significantly associated with the seascape distances separating the sampling sites (A. millepora: $\mathrm{p}=0.002 ;$. damicornis: $\mathrm{p}=0.001$ and $P$. acuta: $\mathrm{p}=0.001 ;$ Fig. 3 ). This relationship was more stressed in the two Pocillopora species, where connectivity proxies (i.e. dbMEMs) explained a larger part of the variance of the population structure (adjusted coefficient of determination for P. damicornis: $\mathrm{R}_{\mathrm{adj}}{ }^{2}=0.36$; for $P$. acuta: $\mathrm{R}_{\mathrm{adj}}^{2}=0.4$; Fig. 3) compared with A. millepora $\left(\mathrm{R}_{\mathrm{adj}}^{2}=0.12\right)$.

Reef connectivity indices. The seascape connectivity graph was used in the calculation of two indices describing the dispersal characteristics of every reef of New Caledonia (Outbound Connectivity Index, OCI, Fig. 4a; Inbound Connectivity Index, ICI, Fig. 4b). Both indices are expressed in $\mathrm{km}^{2}$, as they represent the area of the reefs neighboring a reef of interest. In OCI, neighboring reefs are those potentially receiving propagules from the reef of interest, while in ICI neighboring reefs are those potentially sending propagules towards the reef of interest.

Reefs that are more distant to Grande Terre (Entrecasteaux, Lifou, Maré and Ouvéa) had lower OCI (average OCI: $202 \pm 35 \mathrm{~km}^{2}, 410 \pm 270 \mathrm{~km}^{2}, 210 \pm 66 \mathrm{~km}^{2}, 864 \pm 254 \mathrm{~km}^{2}$, respectively; Fig. $4 \mathrm{a}$ ) than reefs surrounding Grande Terre. Reefs surrounding Grande Terre showed highest values on the southern reefs of the eastern coast 


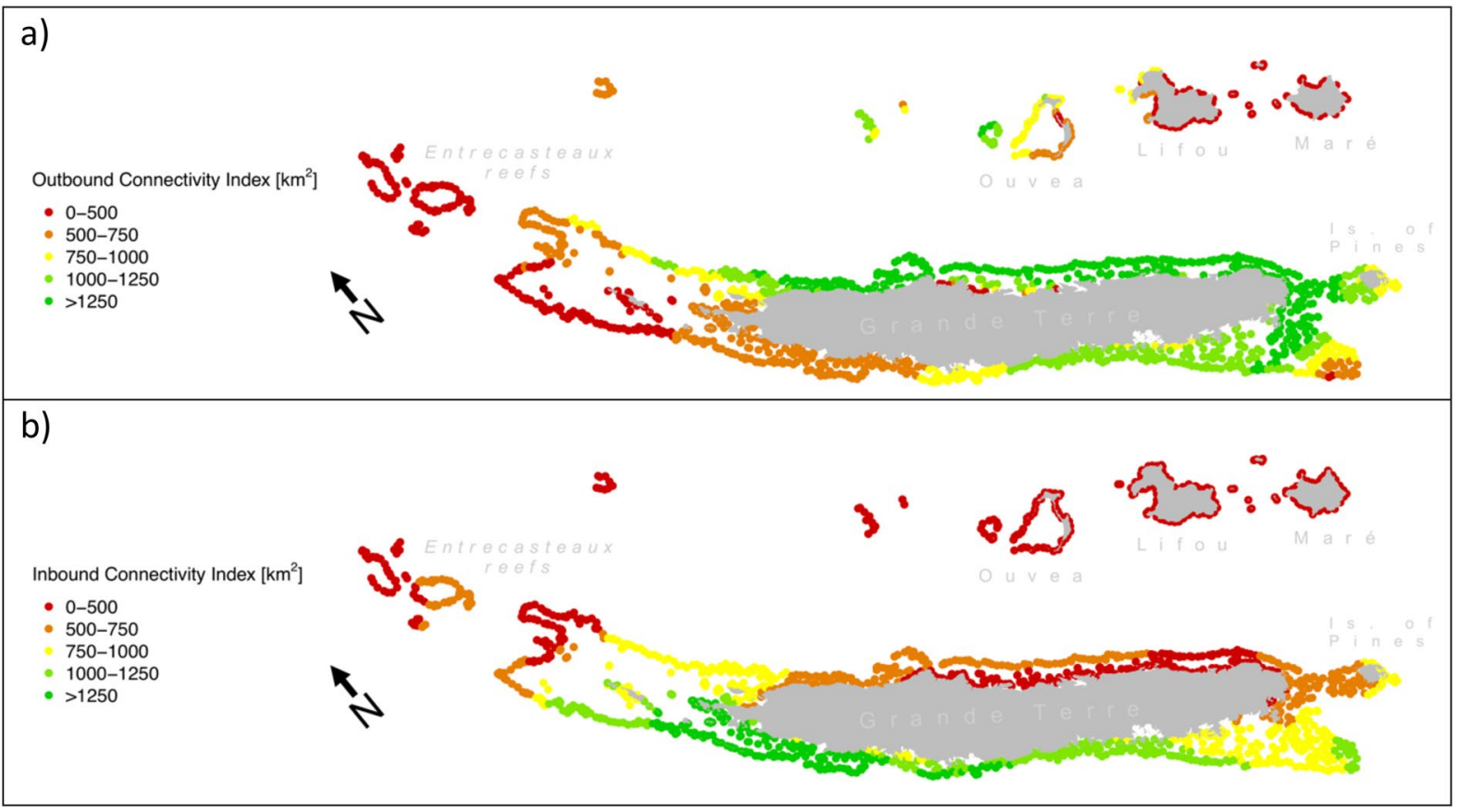

Figure 4. Connectivitiy indices. Two connectvitiy indices based on sea current data are shown for every reef of New Caledonia. In a), the Outbound Connectivity Index (OCI) describes the predisposition in sending dispersal to neighboring reefs. In b), the Inbound Connectivity Index (ICI) summarizes the predisposition in receiving propagules from neighboring reefs. Both indices are given in $\mathrm{km}^{2}$, as this represents the total surface of neighboring reefs. Maps prepared using R (v. $3.5^{53}$ ).

$\left(1929 \pm 300 \mathrm{~km}^{2}\right)$, while lower values were predicted for the rest of the eastern coast $\left(1377 \pm 435 \mathrm{~km}^{2}\right)$ and the southern part of the western coast $\left(1119 \pm 82 \mathrm{~km}^{2}\right)$. OCI was lower at reefs located at the northern extremity of Grande Terre $\left(632 \pm 244 \mathrm{~km}^{2}\right)$.

Like with OCI, ICI was lower at reefs furthest from Grande Terre (Entrecasteaux, Ouvéa, Lifou, Maré; average ICI of $460 \pm 93 \mathrm{~km}^{2}, 177 \pm 7 \mathrm{~km}^{2}, 97 \pm 30 \mathrm{~km}^{2}, 111 \pm 6 \mathrm{~km}^{2}$, respectively; Fig. $\left.4 \mathrm{~b}\right)$. ICI at reefs surrounding Grande Terre displayed a net contrast between the east and west coasts, where ICI was lower on the east $\left(498 \pm 113 \mathrm{~km}^{2}\right)$ than the west $\left(1287 \pm 407 \mathrm{~km}^{2}\right)$.

Coral cover analysis. Underwater surveys of New Caledonian reefs were analyzed to characterize the association of living coral cover with recent thermal stress $\left(\mathrm{BAF}_{\text {previous year }}\right)$, probability of heat stress adaptation $\left(\mathrm{PA}_{\mathrm{HEAT}}\right)$ and connectivity indices (ICI and OCI; Fig. 5). We first investigated the association between coral cover and individual explanatory variables using single fixed effect GLMMs (Fig. 5a-d). We found that coral cover was significantly associated with $\operatorname{BAF}_{\text {previous year }}(\mathrm{p}=0.02)$, and that this association was of negative sign $(\beta=-0.06 \pm 0.03$; Fig. $5 \mathrm{a})$. In contrast, none of the other univariate models resulted in a significant association with coral cover (PA ${ }_{\text {HEAT }} p=0.30$, Fig. $5 b ;$ OCI: $p=0.21$, Fig. $5 c ;$ ICI: $p=0.47$, Fig. $\left.5 d\right)$. The Akaike Information Criterion (AIC) suggested a higher quality-of-fit for the model employing $\mathrm{BAF}_{\text {previous year }}$ as explanatory variable $(\mathrm{AIC}=-883)$, compared with the other univariate models $\left(\mathrm{PA}_{\mathrm{HEAT}}\right.$ : $\mathrm{AIC}=-879$; $\mathrm{OCI}$ : $\mathrm{AIC}=-880$, ICI: $\mathrm{AIC}=-879$ ).

We then investigated whether the negative association between coral cover and $\mathrm{BAF}_{\text {previous year }}$ varied under different values of $\mathrm{PA}_{\mathrm{HEAT}}$, OCI or ICI. This analysis employed three bivariate GLMM setting as fixed effects $\mathrm{BAF}_{\text {previous year }}$ and the interaction between $\mathrm{BAF}_{\text {previous year }}$ and each of the three other explanatory variables $\left(\mathrm{PA}_{\mathrm{HEAT}}, \mathrm{OCI}, \mathrm{ICI}\right.$; Fig. 5e-g). In comparison to all the univariate models, those accounting for the interaction of $\mathrm{BAF}_{\text {previous year }}$ with $\mathrm{PA}_{\mathrm{HEAT}}$ and ICI resulted in a higher quality-of-fit $(\mathrm{AIC}=-886$ and $\mathrm{AIC}=-888$, respectively). In both cases, the effect of $\mathrm{BAF}_{\text {previous year }}$ was significant $(\mathrm{p}<0.01)$ and of negative sign, whereas the effect of the interaction was also significant but of positive sign (for the interaction with $\mathrm{PA}_{\mathrm{HEAT}}$ : $\beta=+0.05 \pm 0.02, \mathrm{p}=0.03$; with ICI: $\beta=+0.07 \pm 0.03, p=0.01$; Fig. $5 e-f)$. In contrast, the bivariate model incorporating OCI had a qualityof-fit comparable to univariate models $(\mathrm{AIC}=-883)$, and showed no significant association in interaction with BAF $_{\text {previous year }}$ (Fig. 5g).

\section{Discussion}

Local divergences in conservation indices. The metrics computed in this study stressed the strong asymmetry, in terms of both probability of heat stress adaptation $\left(\mathrm{PA}_{\mathrm{HEAT}}\right)$ and connectivity (inbound connectivity index, ICI; outbound connectivity index; OCI), between reefs on the two coasts of Grande Terre (Figs. 2a, 4). The climatic differences between the two coasts are modulated by the mountain range covering Grande 
a) Model BAF $_{\text {previous year }}$

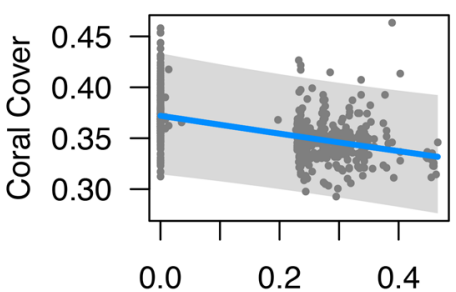

$\mathrm{BAF}_{\text {previous year }}$

c) Model $\mathrm{OCl}$

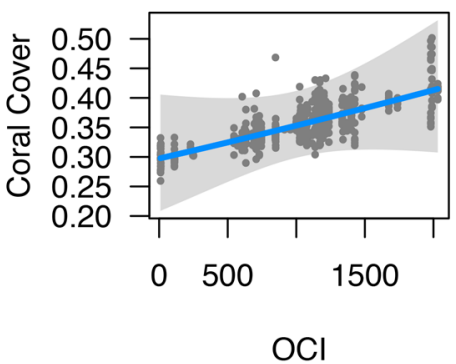

b) Model PAHEAT

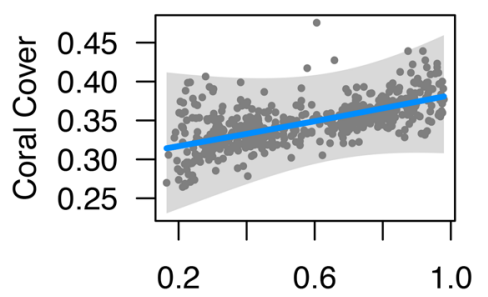

PA $_{\text {HEAT }}$

d) Model ICl

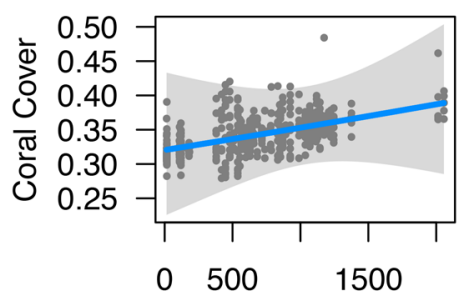

$\mathrm{ICl}$

e) Model $B A F_{\text {previous year }}+\mathrm{BAF}_{\text {previous year }}$ : $\mathrm{PA}$ HEAT $\begin{array}{lllll}0.0 & 0.1 & 0.2 & 0.3 & 0.4\end{array}$

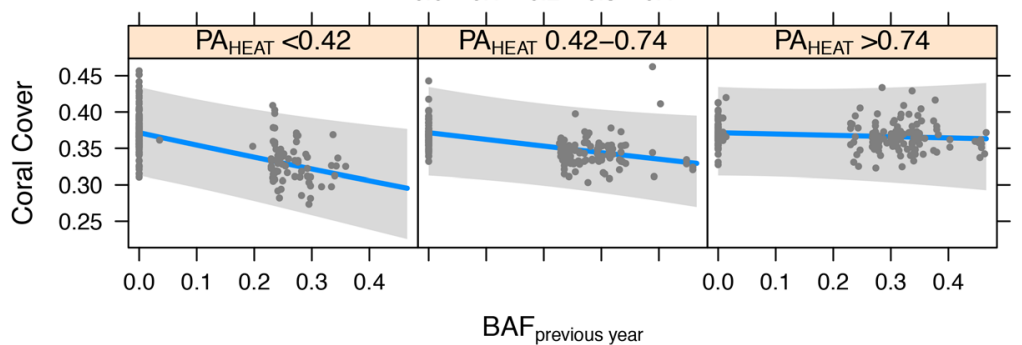

f) Model $\mathrm{BAF}_{\text {previous year }}+\mathrm{BAF}_{\text {previous year }}: \mathrm{OCI}$

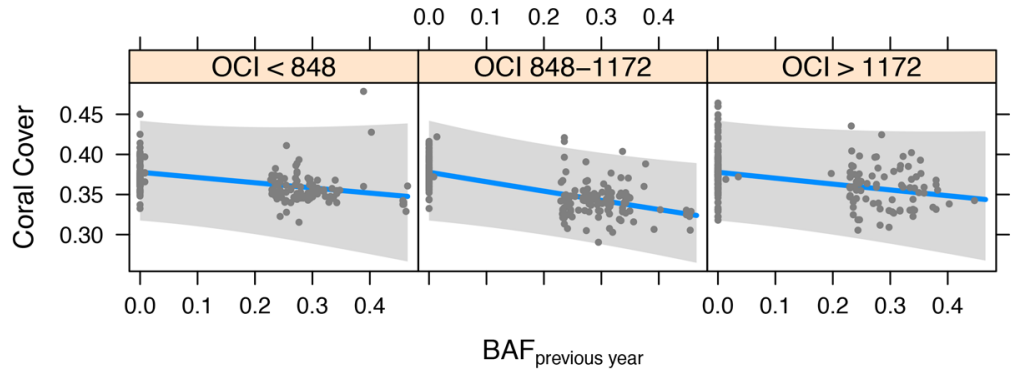

g) Model $B A F_{\text {previous year }}+\mathrm{BAF}_{\text {previous year }}: \mathrm{ICl}$

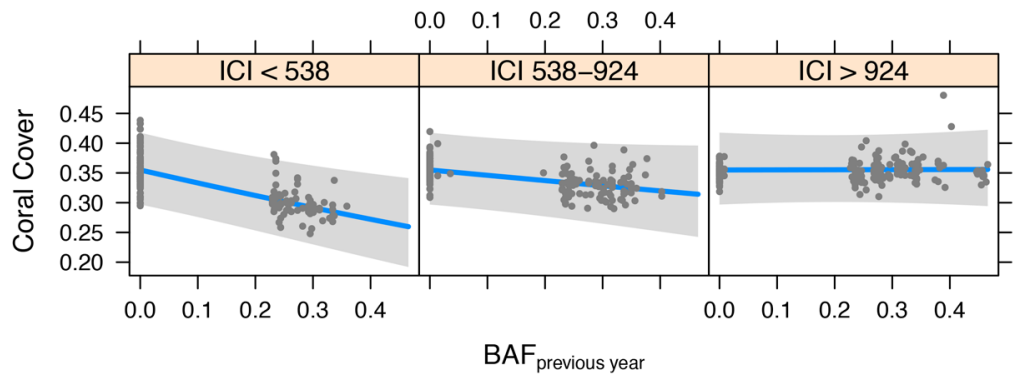

Figure 5. Coral cover association analysis. The plots display the association of coral cover rates (blue line, with the grey band showing the $95 \%$ interval of confidence) with recent thermal stress $\left(\mathrm{BAF}_{\text {previous year }}\right)$, probability of heat stress adaptation $\left(\mathrm{PA}_{\mathrm{HEAT}}\right)$ and connectivity indices (inbound connectivity index, ICI, and outbound connectivity index, OCI). In plots (a) to (d), the association with coral cover rates is shown for each explanatory variable alone ( $\mathrm{a}: \mathrm{BAF}_{\text {previous year }} \mathrm{b}: \mathrm{PA}_{\mathrm{HEAT}}, \mathrm{c}: \mathrm{OCI}, \mathrm{d}$ : ICI). In the remaining plots, the association between coral cover and $\mathrm{BAF}_{\text {previous year }}$ and is showed across different ranges $\mathrm{PA}_{\mathrm{HEAT}}(\mathbf{e}), \mathrm{OCI}(\mathbf{f})$ and ICI $(\mathbf{g})$. 
Terre, and water conditions inside the lagoon reflect the combination of these differences coupled with oceanic influences ${ }^{25}$. For example, the southern part of the west coast of Grande Terre is subjected to coastal upwelling, a seasonal phenomenon bringing cold water to the surface ${ }^{26}$. While logic would suggest that cold water alleviates heat stress, research on the Great Barrier Reef in Australia showed that intense upwelling is followed by severe heat stress, and consequent coral bleaching ${ }^{27}$. While it is unknown whether this same effect occurs on the south-western coast of Grande Terre, this region does enclose the reefs that are predicted to experience the highest frequency of bleaching conditions across New Caledonia, and consequently to host corals with the highest $\mathrm{PA}_{\text {HEAT }}$ (Fig. 2).

Asymmetrical spatial patterns between the coasts of Grande Terre were also predicted for connectivity (Fig. 4), and this matched the genetic population structure of corals of the region (Fig. 3). In this work, we estimated connectivity using a straightforward approach, conceived to be reproduceable on any reef system around the world but that might lead to local inaccuracies ${ }^{17}$. However, our predictions were generally consistent with previous work that characterized the regional water circulation around New Caledonia using more sophisticated methods (i.e. combining oceanographic models, in situ measurements and shipboard detectors of sea currents) ${ }^{28}$. For instance, we observed a higher inbound connectivity index (ICI) on the west coast of Grande Terre (Fig. 4b), and a higher outbound connectivity index (OCI) on the east coast (Fig. 4a). This west-oriented connectivity was expected because of the South Equatorial Current crossing the archipelago in this direction ${ }^{28}$. This current bifurcates at the encounter of the New Caledonian shelf into (1) a weak and transient south-east oriented current between the Loyalty Islands and Grande Terre, and (2) a strong north-west oriented current flowing north of the Loyalty Islands ${ }^{26,28,29}$. This bifurcation explains the lower OCI observed in Lifou and Maré, compared with Ouvéa and the Astrolabe atolls. Last, the water circulation inside the lagoon follows the north-west orientation of trade winds ${ }^{26}$, resulting in higher OCI in the south and higher ICI in the north.

Predictions of reef connectivity and $\mathrm{PA}_{\mathrm{HEAT}}$ varied considerably across the different regions of the study area (Figs. 2, 4), and conservation planning should account for these regional peculiarities ${ }^{14,30}$. In Table 1, we interpret the local divergences in values of $\mathrm{PA}_{\mathrm{HEAT}}$, ICI and OCI under a conservation perspective.

Predictions on adaptive potential match coral cover. Heat exposure is considered to be one of the main drivers of coral mortality worldwide ${ }^{11,31,32}$. Our results were consistent with this view, as we found a significant negative association of coral cover with $\mathrm{BAF}_{\text {previous year }}$ (Fig. 5a). Adaptation might contribute to increase thermal tolerance in corals, but its potential depends on two elements: the existence of adapted corals and the presence of reef connectivity patterns facilitating their dispersal. In this study, we found both of these elements $\left(\mathrm{PA}_{\mathrm{HEAT}}\right.$ and ICI) as associated with reduced loss of coral cover after thermal stress.

Previous studies have reported reefs that display increased thermal tolerance after recurrent exposure to heat stress $^{7-11}$, and recent research suggested that the thermal contrasts of New Caledonia might have driven adaptive processes in corals of the region ${ }^{23}$. Our results supported this view: while recent thermal stress $\left(\mathrm{BAF}_{\text {previous year }}\right)$ was associated with a reduction in coral cover, this reduction was mitigated at reefs that have experienced past thermal stress and were therefore predicted with high $\mathrm{PA}_{\mathrm{HEAT}}$ (Fig. 5e). In addition, $\mathrm{PA}_{\mathrm{HEAT}}$ alone did not result in a significant association with coral cover rates (Fig. 5b), and this might be due to the fact that thermal adaptation is advantageous only in response to heat stress. Indeed, previous research reported trade-offs in traits involved in local adaptation and acclimatization to heat stress in corals ${ }^{33}$. These trade-offs might explain why the highest rates of coral cover $(>0.4)$ in absence of heat stress $\left(\mathrm{BAF}_{\text {previous year }}=0\right)$ were mainly observed at reefs with low $\mathrm{PA}_{\mathrm{HEAT}}$ (Fig. 5e).

Outbound connectivity was not found to be associated with changes in coral cover (Fig. $5 c$,f). This is not surprising, because beneficial effects of dispersal are expected at reefs receiving incoming propagules, rather than the opposite $^{16,34}$. Indeed, inbound connectivity was found to mitigate the negative association between $\mathrm{BAF}_{\mathrm{p}}$ and coral cover (Fig. 5g). Two non-mutually exclusive reasons might explain this observation. First, high levels of incoming propagules might facilitate the turnover of dead colonies caused by heat stress ${ }^{35}$, although it has to be noted that this kind of recovery usually requires several years ${ }^{36}$. Second, incoming dispersal facilitates the arrival of adapted propagules, and therefore promotes an adaptive response even at reefs that did not experience thermal stress before ${ }^{37}$. Indeed, we observed that the frequency of adaptive genotypes in A. millepora and P. acuta was generally higher at reefs predicted with low $\mathrm{PA}_{\mathrm{HEAT}}$ and high ICI, than in those predicted with both low $\mathrm{PA}_{\mathrm{HEAT}}$ and low ICI (Fig. S2). This view on genetic rescue via incoming migration is supported by the fact that every reef depends, to some extent, on its neighbors for larval recruitment ${ }^{38}$.

Limitations and future directions. The associations found between changes in coral cover and the descriptors of thermal stress, probability of heat stress adaptation and connectivity do not necessarily imply causative relationships. Despite evidence of effects of thermal patterns on coral cover reported by previous studies, there might be other environmental constraints that are asymmetrical between the two coasts of Grande Terre and modulate coral cover changes. Further validation remains necessary and could be achieved via experimental assays of heat stress resistance ${ }^{8}$ in colonies sampled at reefs with different $\mathrm{PA}_{\mathrm{HEAT}}$. This approach would also enable disentangling of the possible confounding role of acclimatization in heat stress adaptive responses ${ }^{12,33}$.

Another important aspect to consider in future studies is the resolution of remote sensing datasets used for predictions. Here, we worked at a resolution of $\sim 5 \mathrm{~km}$ for thermal variables and $\sim 8.5 \mathrm{~km}$ for sea current data. While the overall environmental patterns appeared consistent with those characterized in previous studies, it is likely that small scale phenomena were neglected. For instance, reef heat stress exposure can vary substantially under the fine-scale $(<1 \mathrm{~km})$ of a seascape ${ }^{13}$. The same applies to connectivity, since the use of high resolution $(\leq 1 \mathrm{~km})$ hydrodynamic models could improve the characterization of coral larvae fine-scale dispersal ${ }^{39,40}$. 


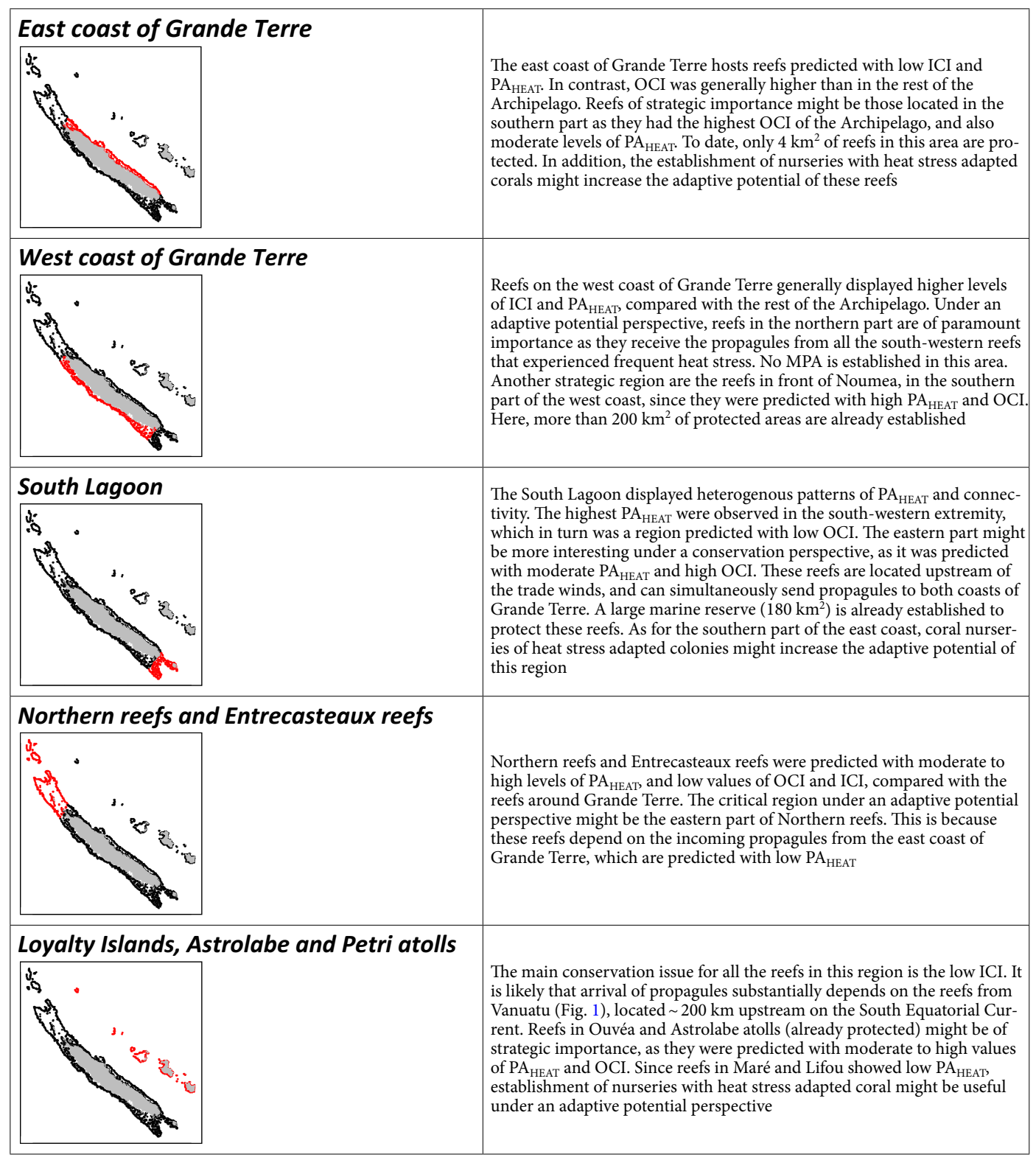

Table 1. Implications for reef conservation in New Caledonia. The table describes the implications for reef conservation of the probability of heat stress adaptation $\left(\mathrm{PA}_{\mathrm{HEAT}}\right)$, the outbound and inbound connectivity indices (OCI, ICI) predicted for different regions of the New Caledonia reef system. Information on the existing marine protected areas were retrieved from the French agency for MPAs (https://www.aires-marin es.fr/). Maps prepared using R (v. $\left.3.5^{53}\right)$.

A third limitation of our approach concerns the generalization of the biological and ecological characteristics of a reef. Here we assumed that the reef system of New Caledonia was a single homogenous ecological niche, hosting an "average" species with an "average" heat stress adaptive response. This simplification is useful to portray an overall prediction, but might lead to local inaccuracies. This is because the reef types of New Caledonia are variegated and species distributions varies accordingly ${ }^{41,42}$. Furthermore, different species have different levels of bleaching sensitivity ${ }^{43}$ and reproduce under different strategies ${ }^{44}$. For instance, the propagules of a broadcast spawning coral as A. millepora travel over longer distances, compared with those of brooding species as $P$. damicornis and P. acuta ${ }^{45}$. Consequently, the goodness-of-fit of models associating population structure and connectivity at the scale of New Caledonia was lower for A. millepora, when compared to the Pocillopora species (Fig. 3). Differences in the dispersal range can also modulate adaptive processes, since limited dispersal capabilities magnify the strength of natural selection ${ }^{46}$. The result are sharper gradients of adaptive genotype frequencies that in our study were not observed. Indeed, the accuracy in predicting the expected frequencies of adaptive genotypes did not significantly differ between species (Fig. S1), even though this observation might be biased by the unbalanced sample size between species ${ }^{47}$. 
In future studies, $\mathrm{PA}_{\mathrm{HEAT}}$ and connectivity predictions should be calibrated to match these biological differences. It is for this reason that seascape genomics studies will become of paramount importance into the future, as they provide species-specific indications on (1) how thermal stress might be translated in probability adaptation, and (2) the biological meaning (e.g. degree of genetic separation) of a cost distance by sea currents ${ }^{17,18}$.

Conclusions. In this study, we combined remote sensing of environmental conditions with genomic data to predict spatial patterns of heat stress adaptation and connectivity for the coral reefs of New Caledonia. We then retrieved field survey data and showed that recent heat stress was associated with a decrease in living coral cover, but also that such association appeared to be mitigated at reefs predicted with (1) high probability of heat stress adaptation and (2) high levels of incoming dispersal. The metrics computed in this work resumes the adaptive potential of corals against heat stress, and therefore represents valuable indices to support spatial planning of reef conservation.

\section{Methods}

Remote sensing of sea surface temperature. Satellite data characterizing sea surface temperature (SST) were retrieved from a publicly available database (dataset: ESA SST CCI reprocessed sea surface temperature analyses $)^{48,49}$. This dataset provides daily records of SST at a $\sim 5 \mathrm{~km}$ resolution from the years 1981 to 2017 across the whole study area (Fig. 1). The shapes of the reef of the region ${ }^{50}$ were transformed into a regular grid $(1,284$ cells with maximal size of $5 \times 5 \mathrm{~km})$, and for each reef cell we extracted the average temperature for every day of the observational period using QGIS software (v. 3.14) $)^{51}$.

We performed calculations of heat stress patterns in the R environment (v. 3.5) using the raster package (v. $3.0)^{52,53}$. For each reef cell, patterns of heat stress were computed using the bleaching alert definition developed by the Coral Reef Watch briefly described hereafter ${ }^{20}$. For every day, we calculated the "hotspot value" as the difference between SST and the maximal monthly mean (MMM, usually the monthly average of February in New Caledonia). The hotspot value was retained only when SST exceeded the MMM by at least $1{ }^{\circ} \mathrm{C}$. Next, for each day, we calculated the cumulated hotspot values over the previous 84 days ( 3 months), and if this sum is $>0$, the day is flagged as being 'under bleaching alert'. Finally, we computed the frequency of days under bleaching alert for every year $\left(\mathrm{BAF}_{\text {year }}\right)$ from 1985 to 2017. For the preceding years (1981-1984), $\mathrm{BAF}_{\text {year }}$ was not calculated such to avoid bias caused by estimating MMM over a limited number of years. An overall measure of BAF $\left(\mathrm{BAF}_{\text {overall }}\right)$ was calculated as the average of all the $\mathrm{BAF}_{\text {year }}$ from 1985 to 2017.

Seascape connectivity graph. For the estimation of connectivity we applied a method based on spatial graphs previously employed to study coral reef connectivity ${ }^{17}$ and briefly outlined hereafter. We retrieved a publicly available dataset describing the eastward and northward surface water velocity (Global Ocean Physics Reanalysis $)^{48}$. This dataset provided daily records at $\sim 8.5 \mathrm{~km}$ resolution from 1993 to 2017 . Since this resolution can be inaccurate close to coastlines, we increased the resolution to $1 \mathrm{~km}$ using the "resample" function ("bilinear" method) of the raster $\mathrm{R}$ package, and used high resolution bathymetry data ( $100 \mathrm{~m}$ resolution $\left.{ }^{54}\right)$ to remove the sea velocity value from pixels located on land. We then used the R package gdistance (v. 1.2) $)^{55}$ to create a matrix describing the transition costs between each adjacent pixel in the study area. These costs were inversely proportional to the frequency of transition based on sea currents. This seascape connectivity graph was calculated as the shortest cost distances across this matrix between for each pair of the 1,284 reef cells. Of note, two least-costpaths were calculated for each pair of reef cells, one for each direction of the transition.

Connectivity indices. The seascape connectivity graph was used to compute two indices connectivity for every reef cell of the study area: inbound connectivity and outbound connectivity. These indices had been defined in previous work on corals ${ }^{17}$ and were calculated in the $\mathrm{R}$ environment.

- Outbound connectivity index (OCI): represents the predisposition of a reef to send coral propagules to its neighbors. For a given reef cell, it is calculated by defining all the neighboring reef cells that can be reached under a determined cost distance threshold (CDt). OCI is the total area (in $\mathrm{km}^{2}$ ) of the destination reef cells.

- Inbound connectivity index (ICI): represents the predisposition of a reef to receive coral recruits from its neighbors. For a given reef cell, it is calculated by defining all the neighboring reef cells that can reach this target reef cell under a determined CDt. ICI is the total area $\left(\mathrm{in} \mathrm{km}^{2}\right)$ of these departure reef cells.

We set the value of CDt to 800 units in order to maximize the neighborhood extent without causing border effects. This value was calculated based on the reef cells' cost distance to and from the borders of the study area (located $\sim 250 \mathrm{~km}$ around the most peripheral reef cells; Fig. S3), where the minimal cost distances to and from the border were 836 and 801 units, respectively.

SNPs dataset. We retrieved genomic data employed in previous seascape genomics analyses on three coral species of New Caledonia: Acropora millepora, Pocillopora damicornis and Pocillopora acuta ${ }^{23}$. This dataset encompassed more than one hundred individuals per population (167 in A. millepora, 118 in P. damicornis, 110 in $P$. acuta), collected at multiple sampling sites around Grande Terre (20 sites for A. millepora, 17 for P. damicornis, 17 for $P$. acuta) and genotyped using a Genotype-By-Sequencing approach ${ }^{56}$ characterizing thousands of single-nucleotide-polymorphisms (SNPs; 11,935 in A. millepora, 7,895 in P. damicornis and 8,343 in P. acuta). Of note, SNPs in this dataset were already filtered for rare allelic variants (minor allele frequency $<0.05 \%$ ) and linkage disequilibrium (LD-pruning threshold $=0.3^{57}$ ). 
Probability of heat stress adaptation. The previous seascape genomics study investigated the genotype-environment associations between SNPs and 47 environmental descriptors (among which is $\mathrm{BAF}_{\text {overall }}$ ) using LFMM software ${ }^{23,58}$. In each of the three species, the analysis reported significant associations $(q<0.01)$ of $\mathrm{BAF}_{\text {overall }}$ with potentially adaptive SNPs (10 in A. millepora, 18 in P. damicornis, and 4 in $P$. acuta). We employed these genotype-environment associations to predict the probability of heat stress adaptation $\left(\mathrm{PA}_{\mathrm{HEAT}}\right)$ from $\mathrm{BAF}_{\text {overall }}$ values. We used a method based on logistic regressions ${ }^{21,59}$ that was previously applied to corals ${ }^{17}$, with some modifications outlined hereafter.

First, we evaluated the accuracy of the approach. For each individual used in the analysis, we retrieved the $\mathrm{BAF}_{\text {overall }}$ value at the sampling location. Next, we encoded the presence/absence of the every putatively adaptive genotype as a binary variable using a custom function in the R environment. For every putatively adaptive genotype, we constructed a logistic genotype-environment association model with $\mathrm{BAF}_{\text {overall }}$. These models define the expected frequency of a genotype of interest for a given $\mathrm{BAF}_{\text {overall }}$ value. We evaluated the predictive accuracy of every model by running a cross-validation using a "leave-one-population-out" approach. This approach consisted in excluding all samples from one sampling site during model training, and then in using the model to predict the expected genotype frequency at that site. This procedure was reiterated for every sampling site, and the correlation (Pearson) between the observed and expected genotype frequencies was calculated for every putatively adaptive genotype. As a comparison, we applied the same cross-validation method for 1000 genotypes randomly selected in each of the three species.

Next, we employed a generalize linear mixed model (GLMM) to build an overall genotype-environment association model combining all the putatively adaptive genotypes across the three species. This was done through the R package $\operatorname{glmm} T M B(\mathrm{v} 1.0)^{60}$, using a logistic regression model where genotype identifier, sample identifier and species were introduced as random factor. The resulting model then was used to transform $\mathrm{BAF}_{\text {overall }}$ values associated with each of the 2,284 reef cells of New Caledonia in $\mathrm{PA}_{\mathrm{HEAT}}$. The model was plotted using the visreg R package (v. 2.6.1)

Reef connectivity and genetic structure of coral populations. The SNPs dataset was used to evaluate whether reef connectivity predictions based on seascape graph were representative proxies of the genetic structure of three coral populations. The method we used is based on redundancy analysis (RDA) and has already been applied to marine invertebrates ${ }^{62,63}$. This approach is an ordination technique investigating the relationship between (1) the axes of variation of a matrix describing allelic frequencies among sites and (2) the axes of variation of a matrix describing the distances (according to the seascape graph) between sites. For every species, we performed the analysis in the $\mathrm{R}$ environment as outlined hereafter.

By using a custom $\mathrm{R}$ function, we first computed the minor allele frequency (MAF) of every SNP at every sampling site having at least 5 samples (18 sites for A. millepora, 10 for $P$. damicornis and $P$. acuta). The resulting matrix of allele frequencies was then transformed using the Hellinger approach as suggested by Legendre $\&$ Gallagher $^{64}$. Next, a principal component analysis (PCA) of the allele frequencies matrix was performed using the "prcomp" R function (stats package, v. 3.5). The first principal components (PCs) that cumulatively explained $80 \%$ of the total variation were kept and used as response table for the RDA.

The seascape graph was used to calculate the least-cost-path between every pair of sampling sites using the "costDistance" function (R package gdistance, v. 1.2) ${ }^{55}$. Next, we computed the distance-based Moran's eigenvector maps (dbMEMs) ${ }^{65}$ based on the least-cost-path between sites using the "pcnm" function of the vegan R package (v. 2.5) ${ }^{66}$. dbMEMs are spatial orthogonal variables decomposing the distances between sites as described in the least-cost-path matrix. The table of dbMEMs was used as explanatory table for the RDA.

Finally, we performed RDA using "rda" function (vegan package). We employed the genetic PCA table as response table and the dbMEMs table as explanatory table. By using the "ordistep" function (vegan package), we identified the dbMEMs that best explained the variability of the PCA axes, i.e. the "optimal" model based on the adjusted coefficient of determination $\left(\mathrm{R}_{\mathrm{adj}}^{2}\right)$. We assessed the global significance of the "optimal model" using an analysis of variance ("anova" function, 1000 permutations), and graphically visualized the distribution of sampling sites and dbMEMs across the RDA axes.

Coral cover data. Living coral cover data was retrieved from the 2017-18 report of the New Caledonian observational network of coral reefs ('Réseau d’observation des récifs coralliens de Nouvelle Calédonie', RORC ${ }^{24}$ ). Overall, we used data from 74 survey stations distributed across the Archipelago of New Caledonia (Fig. 1). At each station, yearly coral cover surveys were performed along the same $100 \mathrm{~m}$ transect using the "point intercept" technique. Surveys covered the period from 2003 to 2017, where 18 sites have been visited for less than five years, 27 for five to ten years, and 29 for more than ten years. The exact coordinates of survey stations were retrieved from the geographic information web-portal of New Caledonia (https://georep.nc/).

Environmental characterization of survey sites. The coordinates of survey stations were used to find the corresponding reef cells and the associated values of the connectivity indices (OCI and ICI). For each survey record (i.e. survey at a given station in a specific year) we also calculated $\mathrm{BAF}_{\text {overall }}$ as the average $\mathrm{BAF}$ since 1985 to two years before the survey. Based on the values of $\mathrm{BAF}_{\text {overall }}$ we computed $\mathrm{PA}_{\mathrm{HEAT}}$ for each survey record. In addition, we calculated BAF values on a rolling temporal window describing average BAF for the year $\left(\mathrm{BAF}_{\text {previous year }}\right)$ that preceded the year of survey.

Analysis of coral cover change. We investigated the association of $\mathrm{BAF}_{\text {previous year }}, \mathrm{PA}_{\mathrm{HEAT}}$ and connectivity indices (ICI and OCI; in total 4 explanatory variables) with coral cover rates (response variable) using GLMMs. This analysis focused on the coral cover rates of every survey record (total of 574 records). The computation 
of GLMMs was performed using the R package glmmTMB ${ }^{60}$, which allowed us to model coral cover rates via beta regression ${ }^{67}$. We accounted for the non-independence of survey records originated at the same station but on different years by setting the station effect as random factor on the coral cover rate ${ }^{68}$. This approach is recommended for studies of longitudinal data with irregular time points ${ }^{69}$. To avoid bias due to scale differences between explanatory variables, each variable was standardized to mean 0 and standard deviation 1 using the $\mathrm{R}$ "scale" function.

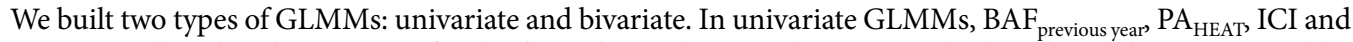
OCI were employed each as unique fixed effect. The goal was to determine whether the explanatory variables showed a standalone association (i.e. independent from other variables) with coral cover change. In bivariate models, GLMMs were constructed each with two fixed effects: (1) BAF previous year $_{\text {and }}$ (2) the interaction between $\mathrm{BAF}_{\text {previous year }}$ and each of the remaining explanatory variables: $\mathrm{PA}$ HEAT $\mathrm{ICI}$ and $\mathrm{OCI}$. The goal of bivariate models was to investigate whether the potential effect of recent thermal stress $\left(\mathrm{BAF}_{\text {previous year }}\right)$ on coral cover might be modulated by $\mathrm{PA}_{\mathrm{HEAT}}$, ICI or OCI.

For each GLMM, we reported the estimate and its standard deviation, as well as the p-value (deemed significant when $<0.05$ ) associated with Wald statistic ${ }^{60}$ of the fixed effects. In addition, we compared the quality-of-fit of models by calculating the Akaike Information Criterion (AIC) ${ }^{70}$.

\section{Data availability}

Data and scripts used in this work are available on Zenodo (https://doi.org/10.5281/zenodo.4227641).

Received: 5 June 2020; Accepted: 21 October 2020

Published online: 12 November 2020

\section{References}

1. Hughes, T. P. et al. Global warming and recurrent mass bleaching of corals. Nature 543, 373-377 (2017).

2. Bellwood, D. R., Hughes, T. P., Folke, C. \& Nyström, M. Confronting the coral reef crisis. Nature 429, 827-833 (2004).

3. Hughes, T. P. et al. Spatial and temporal patterns of mass bleaching of corals in the Anthropocene. Science 359, 80-83 (2018).

4. Van Hooidonk, R., Maynard, J. A. \& Planes, S. Temporary refugia for coral reefs in a warming world. Nat. Clim. Chang. 3, 508-511 (2013).

5. Costanza, R. et al. Changes in the global value of ecosystem services. Glob. Environ. Chang. 26, 152-158 (2014).

6. Moberg, F. \& Folke, C. Ecological goods and services of coral reef ecosystems. Ecol. Econ. 29, 215-233 (1999).

7. Hughes, T. P. et al. Ecological memory modifies the cumulative impact of recurrent climate extremes. Nat. Clim. Change 9, 40-43 (2019).

8. Krueger, T. et al. Common reef-building coral in the northern red sea resistant to elevated temperature and acidification. R. Soc. Open Sci. 4, 170038 (2017).

9. Penin, L., Vidal-Dupiol, J. \& Adjeroud, M. Response of coral assemblages to thermal stress: are bleaching intensity and spatial patterns consistent between events?. Environ. Monit. Assess. 185, 5031-5042 (2013).

10. Thompson, D. M. \& van Woesik, R. Corals escape bleaching in regions that recently and historically experienced frequent thermal stress. Proc. Biol. Sci. 276, 2893-2901 (2009).

11. Sully, S., Burkepile, D. E., Donovan, M. K., Hodgson, G. \& van Woesik, R. A global analysis of coral bleaching over the past two decades. Nat. Commun. 10, 1-5 (2019).

12. Thomas, L. et al. Mechanisms of thermal tolerance in reef-building corals across a fine-grained environmental mosaic: lessons from Ofu, American Samoa. Front. Mar. Sci. 4, 434 (2018).

13. Bay, R. A. \& Palumbi, S. R. Multilocus adaptation associated with heat resistance in reef-building corals. Curr. Biol. 24, 2952-2956 (2014).

14. Wilson, K. L., Tittensor, D. P., Worm, B. \& Lotze, H. K. Incorporating climate change adaptation into marine protected area planning. Glob. Chang. Biol. 26, 3251-3267 (2020).

15. Baums, I. B. et al. Considerations for maximizing the adaptive potential of restored coral populations in the western Atlantic. Ecol. Appl. 29, (2019).

16. Matz, M. V., Treml, E. \& Haller, B. C. Predicting coral adaptation to global warming in the Indo-West-Pacific. BioRxiv https://doi. org/10.1101/722314 (2019).

17 Selmoni, O., Rochat, E., Lecellier, G., Berteaux-Lecellier, V. \& Joost, S. Seascape genomics as a new tool to empower coral reef conservation strategies: an example on north-western Pacific Acropora digitifera. Evol. Appl. https://doi.org/10.1101/588228 (2020).

18 Riginos, C., Crandall, E. D., Liggins, L., Bongaerts, P. \& Treml, E. A. Navigating the currents of seascape genomics: how spatial analyses can augment population genomic studies. Curr. Zool. https://doi.org/10.1093/cz/zow067 (2016).

19. Maina, J., Venus, V., McClanahan, T. R. \& Ateweberhan, M. Modelling susceptibility of coral reefs to environmental stress using remote sensing data and GIS models. Ecol. Modell. 212, 180-199 (2008).

20. Liu, G., Strong, A. E. \& Skirving, W. Remote sensing of sea surface temperatures during 2002 Barrier Reef coral bleaching. Eos Trans. Am. Geophys. Union 84, 137-141 (2003).

21 Rochat, E. \& Joost, S. Spatial areas of genotype probability (SPAG): predicting the spatial distribution of adaptive genetic variants under future climatic conditions. BioRxiv. https://doi.org/10.1101/2019.12.20.884114 (2019).

22 Boulanger, E., Dalongeville, A., Andrello, M., Mouillot, D. \& Manel, S. Spatial graphs highlight how multi-generational dispersal shapes landscape genetic patterns. Ecography (Cop) https://doi.org/10.1111/ecog.05024 (2020).

23 Selmoni, O. et al. Seascape genomics reveals candidate molecular targets of heat stress adaptation in three coral species. BioRxiv. https://doi.org/10.1101/2020.05.12.090050 (2020).

24. Job, S. New Caledonia network of coral reef observation (RORC) - Field campaign report 2017-2018. (French title: Réseau dobservation des récifs coralliens (RORC) de Nouvelle-Calédonie. Campagne 2017-2018. Rapport Pays. Rapport CORTEX. Pour le compte de: Conservatoire d'espaces naturels de Nouvelle-Calédonie - Province des îles Loyauté - Observatoire de l'environnement). (CORTEX, New Caledonia, 2018).

25. Lefèvre, J., Marchesiello, P., Jourdain, N. C., Menkes, C. \& Leroy, A. Weather regimes and orographic circulation around New Caledonia. Mar. Pollut. Bull. 61, 413-431 (2010).

26. Marchesiello, P., Lefèvre, J., Vega, A., Couvelard, X. \& Menkes, C. Coastal upwelling, circulation and heat balance around New Caledonia’s barrier reef. Mar. Pollut. Bull. 61, 432-448 (2010).

27. Berkelmans, R., Weeks, S. J. \& Steinberga, C. R. Upwelling linked to warm summers and bleaching on the Great Barrier Reef. Limnol. Oceanogr. 55, 2634-2644 (2010).

28. Cravatte, S. et al. Regional circulation around New Caledonia from two decades of observations. J. Mar. Syst. 148, 249-271 (2015). 
29. Hénin, C., Guillerm, J. \& Chabert, L. Circulation superficielle autour de la Nouvelle-Calédonie. Océanographie Trop. 19, 113-126 (1984).

30. Magris, R. A., Pressey, R. L., Weeks, R. \& Ban, N. C. Integrating connectivity and climate change into marine conservation planning. Biol. Cons. 170, 207-221 (2014).

31. Hughes, T. P. et al. Global warming transforms coral reef assemblages. Nature 556, 492-496 (2018).

32. Welle, P. D., Small, M. J., Doney, S. C. \& Azevedo, I. L. Estimating the effect of multiple environmental stressors on coral bleaching and mortality. PLoS ONE 12, e0175018 (2017).

33. Kenkel, C. D., Almanza, A. T. \& Matz, M. V. Fine-scale environmental specialization of reef-building corals might be limiting reef recovery in the Florida Keys. Ecology 96, 3197-3212 (2015).

34. Palumbi, S. R. Population genetics, demographic connectivity, and the design of marine reserves. Ecol. Appl. 13, 146-158 (2003).

35. Hock, K. et al. Connectivity and systemic resilience of the Great Barrier Reef. PLoS Biol. 15, (2017).

36. Robinson, J. P. W., Wilson, S. K. \& Graham, N. A. J. Abiotic and biotic controls on coral recovery 16 years after mass bleaching. Coral Reefs 38, 1255-1265 (2019).

37. Kawecki, T. J. Adaptation to marginal habitats. Annu. Rev. Ecol. Evol. Syst. 39, 321-342 (2008).

38. Treml, E. A. et al. Reproductive output and duration of the pelagic larval stage determine seascape-wide connectivity of marine populations. Integr. Comp. Biol. 52, 525-537 (2012).

39. Storlazzi, C. D., van Ormondt, M., Chen, Y.-L. \& Elias, E. P. L. Modeling fine-scale coral larval dispersal and interisland connectivity to help designate mutually-supporting coral reef marine protected areas: insights from Maui Nui, Hawaii. Front. Mar. Sci. 4, 381 (2017).

40. Colberg, F., Brassington, G. B., Sandery, P., Sakov, P. \& Aijaz, S. High and medium resolution ocean models for the Great Barrier Reef. Ocean Model. 145, 101507 (2020).

41. Andréfouët, S., Cabioch, G., Flamand, B. \& Pelletier, B. A reappraisal of the diversity of geomorphological and genetic processes of New Caledonian coral reefs: A synthesis from optical remote sensing, coring and acoustic multibeam observations. Coral Reefs 28, 691-707 (2009).

42. Dalleau, M. et al. Use of habitats as surrogates of biodiversity for efficient coral reef conservation planning in Pacific Ocean islands. Conserv. Biol. 24, 541-552 (2010).

43. Loya, Y. et al. Coral bleaching: the winners and the losers. Ecol. Lett. 4, 122-131 (2001).

44. Darling, E. S., Alvarez-Filip, L., Oliver, T. A., McClanahan, T. R. \& Côté, I. M. Evaluating life-history strategies of reef corals from species traits. Ecol. Lett. 15, 1378-1386 (2012).

45. Ayre, D. J. \& Hughes, T. P. Genotypic diversity and gene flow in brooding and spawning corals along the great barrier reef, Australia. Evolution (NY) 54, 1590-1605 (2000).

46. Kawecki, T. J. \& Ebert, D. Conceptual issues in local adaptation. Ecol. Lett. 7, 1225-1241 (2004).

47. Selmoni, O., Vajana, E., Guillaume, A., Rochat, E. \& Joost, S. Sampling strategy optimization to increase statistical power in landscape genomics: A simulation-based approach. Mol. Ecol. Resour. 20, (2020).

48. EU Copernicus Marine Service. Global Ocean - In-Situ-Near-Real-Time Observations. (2017). Available at: https://marine.coper nicus.eu. Accessed: 2nd February 2017

49. Merchant, C. J. et al. Satellite-based time-series of sea-surface temperature since 1981 for climate applications. Sci. data 6, 223 (2019).

50. UNEP-WCMC, WorldFish-Center, WRI \& TNC. Global distribution of warm-water coral reefs, compiled from multiple sources including the Millennium Coral Reef Mapping Project. Version 1.3. (2010). Available at: https://data.unep-wcmc.org/datasets/1. Accessed: 9th May 2017

51. QGIS development team. QGIS Geographic Information System. Open Source Geospatial Foundation Project. (2009).

52. Hijmans, R. J. raster: Geographic Data Analysis and Modeling. (2016).

53. R Core Team. R: A Language and Environment for Statistical Computing. (2016).

54. Ryan, W. B. F. et al. Global multi-resolution topography synthesis. Geochemistry, Geophys. Geosystems 10, (2009).

55. van Etten, J. gdistance: Distances and Routes on Geographical Grids. (2018). Available at: https://cran.r-project.org/package=gdist ance.

56. Kilian, A. et al. Diversity arrays technology: A generic genome profiling technology on open platforms. Methods Mol. Biol. 888, 67-89 (2012).

57. Zheng, X. et al. A high-performance computing toolset for relatedness and principal component analysis of SNP data. Bioinformatics 28, 3326-3328 (2012).

58. Frichot, E., Schoville, S. D., Bouchard, G. \& François, O. Testing for associations between loci and environmental gradients using latent factor mixed models. Mol. Biol. Evol. 30, 1687-1699 (2013).

59. Joost, S. et al. A spatial analysis method (SAM) to detect candidate loci for selection: towards a landscape genomics approach to adaptation. Mol. Ecol. 16, 3955-3969 (2007).

60. Brooks, M. E. et al. glmmTMB balances speed and flexibility among packages for zero-inflated generalized linear mixed modeling. R J. 9, 378-400 (2017).

61. Breheny, P. \& Burchett, W. Visualization of regression models using visreg. R J. 9, 56-71 (2017).

62. Xuereb, A., Kimber, C. M., Curtis, J. M. R., Bernatchez, L. \& Fortin, M. Putatively adaptive genetic variation in the giant California sea cucumber ( Parastichopus californicus ) as revealed by environmental association analysis of restriction-site associated DNA sequencing data. Mol. Ecol. 27, 5035-5048 (2018).

63. Benestan, L. et al. Seascape genomics provides evidence for thermal adaptation and current-mediated population structure in American lobster (Homarus americanus). Mol. Ecol. 25, 5073-5092 (2016).

64. Legendre, P. \& Gallagher, E. D. Ecologically meaningful transformations for ordination of species data. Oecologia 129, 271-280 (2001).

65. Borcard, D. \& Legendre, P. All-scale spatial analysis of ecological data by means of principal coordinates of neighbour matrices. Ecol. Modell. 153, 51-68 (2002).

66. Dixon, P. VEGAN, a package of R functions for community ecology. J. Veg. Sci. 14, 927-930 (2003).

67. Ferrari, S. L. P. \& Cribari-Neto, F. Beta regression for modelling rates and proportions. J. Appl. Stat. 31, 799-815 (2004).

68. Verbeke, G., Molenberghs, G. \& Rizopoulos, D. Random effects models for longitudinal data. In Longitudinal Research with Latent Variables 37-96 (Springer, Berlin, 2010). https://doi.org/10.1007/978-3-642-11760-2_2

69. Garcia, T. P. \& Marder, K. Statistical approaches to longitudinal data analysis in neurodegenerative diseases: Huntington's disease as a model. Curr. Neurol. Neurosci. Rep. 17, 14 (2017).

70. Bozdogan, H. Model selection and Akaike's Information Criterion (AIC): the general theory and its analytical extensions. Psychometrika 52, 345-370 (1987).

\section{Acknowledgements}

We thank the Réseau d'observation des récifs coralliens of New Caledonia for collecting and sharing the field survey data. We thank Annie Guillaume and the anonymous reviewers for the comments and suggestions provided during the redaction of this paper. This work was supported by the United Nations Environment Programme 
(UNEP) and International Coral Reef Initiative (ICRI) coral reefs small grants programme (Grant Number: SSFA/18/MCE/005). We also thank the Government of France and the Government of the Principality of Monaco who provided the funding for the small grants.

\section{Author contributions}

OS, GL, VBL and SJ initiated the research. OS retrieved the pre-existing data, computed the conservation indices and ran the statistical analyses, supported by the co-authors. OS wrote the first version of the manuscript, that was the critically revised by the co-authors. All authors read and approved the final version of the manuscript.

\section{Competing interests}

The authors declare no competing interests.

\section{Additional information}

Supplementary information is available for this paper at https://doi.org/10.1038/s41598-020-76604-2.

Correspondence and requests for materials should be addressed to S.J.

Reprints and permissions information is available at www.nature.com/reprints.

Publisher's note Springer Nature remains neutral with regard to jurisdictional claims in published maps and institutional affiliations.

(c) (1) Open Access This article is licensed under a Creative Commons Attribution 4.0 International License, which permits use, sharing, adaptation, distribution and reproduction in any medium or format, as long as you give appropriate credit to the original author(s) and the source, provide a link to the Creative Commons licence, and indicate if changes were made. The images or other third party material in this article are included in the article's Creative Commons licence, unless indicated otherwise in a credit line to the material. If material is not included in the article's Creative Commons licence and your intended use is not permitted by statutory regulation or exceeds the permitted use, you will need to obtain permission directly from the copyright holder. To view a copy of this licence, visit http://creativecommons.org/licenses/by/4.0/.

(C) The Author(s) 2020 